\title{
Progress in designing effective photoelectrodes for solar water splitting
}

\author{
Zhiliang Wang, Lianzhou Wang * \\ Nanomaterials Centre, School of Chemical Engineering and Australian Institute for Bioengineering and Nanotechnology, University of Queensland, \\ St Lucia, QLD 4072, Australia
}

\section{A R T I C L E I N F O}

\section{Article history:}

Received 30 September 2017

Accepted 13 December 2017

Published 5 March 2018

\section{Keywords:}

Solar energy

Hydrogen production

Photoelectrode

Light harvesting

Charge separation

Surface reaction

\begin{abstract}
A B S T R A C T
Photoelectrochemical (PEC) water splitting process is regarded as a promising route to generate hydrogen by solar energy and at the heart of PEC is efficient electrode design. Great progress has been achieved in the aspects of material design, cocatalyst study, and electrode fabrication over the past decades. However, some key challenges remain unsolved, including the most demanded conversion efficiency issue. As three critical steps, i.e. light harvesting, charge transfer and surface reaction of the PEC process, occur in a huge range of time scale (from $10^{-12} \mathrm{~s}$ to $10^{0} \mathrm{~s}$ ), how to manage these subsequent steps to facilitate the seamless cooperation between each step to realize efficient PEC process is essentially important. This review focuses on an integral consideration of the three key criteria based on the recent progress on high efficient and stable photoelectrode design in PEC. The basic principles and potential strategies are summarized. Moreover, the challenge and perspective are also discussed.
\end{abstract}

(C) 2018, Dalian Institute of Chemical Physics, Chinese Academy of Sciences. Published by Elsevier B.V. All rights reserved.

\section{Introduction}

The development of sustainable energy supply has been stimulated by the severity of global energy situation in the aspects of fossil fuel shortage and ecological pollution. Among various attempts, photoelectrochemical (PEC) process has appealed worldwide attention due to its potential in efficiently converting the energy of sunlight into solar fuels such as hydrogen (from solar water reduction) or methanol (from solar $\mathrm{CO}_{2}$ reduction) [1-4]. The past four decades have witnessed the profound progress in the PEC field and the candidates have been widely expanded from the initial metal oxide $\left(\mathrm{Fe}_{2} \mathrm{O}_{3}, \mathrm{TiO}_{2}\right)$ single crystal wafers $[5,6]$ to a library of polycrystalline semiconductors including meatal oxide, sulfide, (oxy)nitride [7-9]. The photoelectrodes based on PS II and dye molecular (Ru complex) have also been reported [10,11]. All these efforts result in a great expansion of the available materials for efficient PEC water splitting.

As a Holy Grail many researchers pursue for [12], PEC hydrogen generation is expected to achieve a solar-to-hydrogen (STH) efficiency over $10 \%$ with a long-term stability (over $1000 \mathrm{~h}$ ) so as to make it a feasible hydrogen production system to compete with conventional hydrogen production in price (2-3 US $\$ \mathrm{~kg}^{-1}$ for the steam reforming of nature gas) $[3,13]$. But until now, the existing photoelectrodes display a low solar conversion capability. More attention should be paid to make it a more efficient, more stable and more economic system.

Many excellent review papers have been published by focusing on the materials design, structure optimization of the photoelectrodes in PEC fields. Herein, we attempt to focus on an integral consideration of the PEC process. It has been widely accepted that the performance of photoelectrode is determined

\footnotetext{
* Corresponding author. Tel: +61-7-33654218; Fax: +61-7-33654199; E-mail: l.wang@uq.edu.au This work was supported by the Australian Research Council through its Discovery Project (DP) and Future Fellowship (FF) Program. DOI: 10.1016/S1872-2067(17)62998-X | http://www.sciencedirect.com/science/journal/18722067 | Chin. J. Catal., Vol. 39, No. 3, March 2018
} 
by its light harvest, charge separation and surface reaction. An effective PEC process not only relies on the efficiency of each step but also needs a seamless cooperation among every step. In this review, we will firstly provide a theoretical analysis of the PEC water splitting process and find the critical factors that limit the performance of solar water pyrolysis. And then some effective strategies to address the problems related to these criteria are summarized for designing effective photoelectrode. Finally, some comments and comparison of different solar hydrogen generation system, e.g., tandem PEC, PV-PEC, and PV-EC are included.

\section{The fundamental of photoelectrochemistry}

In a typical PEC system, photoelectrode/electrolyte system is assembled to a Schottky type photo-diode. A space charge layer will be built in the semiconductor electrode when contacting with electrolyte as a result of Fermi level equilibrium between semiconductor and electrolyte (Fig. 1(a)) [14,15]. When the photoelectrode is excited by light, the band bending in the space charge layer will drive the minority charges (holes for n-type and electrons for p-type semiconductor) moving towards the surface. And if there exists redox couple with suitable energy level to match with the band edge of the semiconductor (Fig. 1(a)), a photo-induced reaction will occur. Based on Gerisher's analysis [16,17], when a PEC water oxidation is expected, the maximum of valance band (VBM) of n-type semiconductor should be higher than the water oxidation potential $\left(E_{\mathrm{H}_{2} \mathrm{O} / \mathrm{O}_{2}}=1.23 \mathrm{~V}\right.$ vs reversible hydrogen electrode (RHE)). And for PEC water reduction, the minimum of conductive band (CBM) of p-type semiconductor should be lower than water reduction potential $\left(E_{\mathrm{H}^{+}} / \mathrm{H}_{2}=0 \mathrm{~V}\right.$ vs RHE). This is a much less strict requirement compared to photocatalysis where the VBM and CBM should straddle the $E_{\mathrm{H}_{2} \mathrm{O} / \mathrm{O}_{2}}$ and $\mathrm{E}_{\mathrm{H}^{+}} / \mathrm{H}_{2}$.

Under an ideal condition where there is no recombination in the space charge layer and the surface chemical reaction is fast enough to release the kinetic bottleneck, the generated photocurrent $(j$ ph $)$ can be calculated based on Gartner equation [18]:

$$
J_{\mathrm{ph}} / I_{0}=1-\exp (-\alpha W) /\left(1+\alpha L_{\mathrm{min}}\right)
$$

where $\alpha$ is the light absorption coefficient, $L_{\min }$ is the diffusion length of minority carrier and $W$ is the width of the space charge layer (Fig. 1(a)), expressed as:

$$
W=\left[\frac{2 \varepsilon_{\mathrm{sc}}\left(E-E_{\mathrm{fb}}\right)}{q N_{\mathrm{d}}}\right]^{1 / 2}
$$

$\varepsilon_{\mathrm{sc}}$ is the dielectric constant, $E_{\mathrm{fb}}$ is the flat band potential, $N_{d}$ is the charge carrier density and $q$ is the elemental charge.

The ideal $j$ - $E$ relationship is an exponential curve (Fig. 1(b)). Yet, in practice, especially for the PEC water oxidation, an ' $\mathrm{S}$ ' type curve with a slow initial step is most frequently observed (Fig. 1(b)). It originates from the dull surface reaction process [15] . At the potential approaching to $E_{\mathrm{fb}}$, there is a low degree of band bending, indicating that there is a low driving force $\left(E-E_{\mathrm{fb}}\right)$ for charge transfer in the space charge layer and serious photocharge recombination will happen via the surface states. Thus, it will generate large deviation from the theoretical curves.

Based on Eq. (1), the ideal photocurrent should have an onset potential of $E_{\mathrm{fb}}$. And a larger $\alpha, L_{\mathrm{min}}, N_{\mathrm{d}}$ all will contribute to

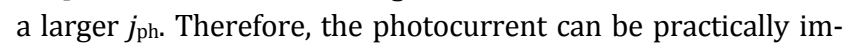
proved by extending the light harvest ability, prolonging the charge diffusion length and improving the carrier density. Furthermore, the surface of the semiconductor should be optimized to reduce the surface charge recombination and improve the charge consumption in order to design efficient photoelectrode. Additionally, Eq. (1) reveals that the maximum limitation $\left(j_{\text {max }}\right)$ of $j_{\text {ph }}$ relies on the intensity $\left(I_{0}\right)$ of captured light determined by the bandgap of a semiconductor (Fig. 1(c)). [3] The claimed photocurrent tested under $100 \mathrm{~mW} \mathrm{~cm}^{-2}$ (AM $1.5 \mathrm{G}$ ) should not excess the integrated photocurrent $j_{\max }$.

Empirically, the practical photocurrent $\left(j_{\mathrm{H} 2 \mathrm{O}}\right)$ for water splitting can be expressed as $[19,20]$ :

$$
j_{\mathrm{H} 2 \mathrm{O}}=j_{\mathrm{ph}} \times \eta_{\mathrm{abs}} \times \eta_{\mathrm{sep}} \times \eta_{\text {inj }}
$$

Where $\eta_{\text {abs, }} \eta_{\text {sep }}$ and $\eta_{\text {inj }}$ are the efficiency of light harvest of the semiconductor, charge separation in the semiconductor and charge injection at the interface of photoelectrode and electrolyte. The three steps occur in a huge time scale ranging from $10^{-12}$ to $10^{0} \mathrm{~s}$ which means that if we want to achieve high performed photoelectrode, the slow surface reaction should (a)

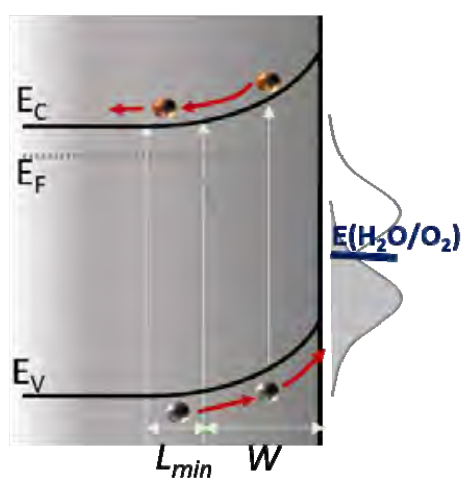

(b)

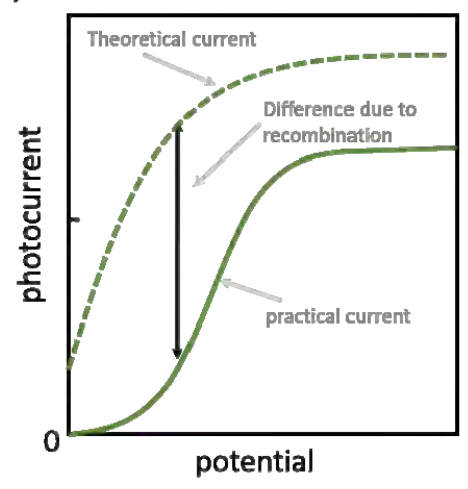

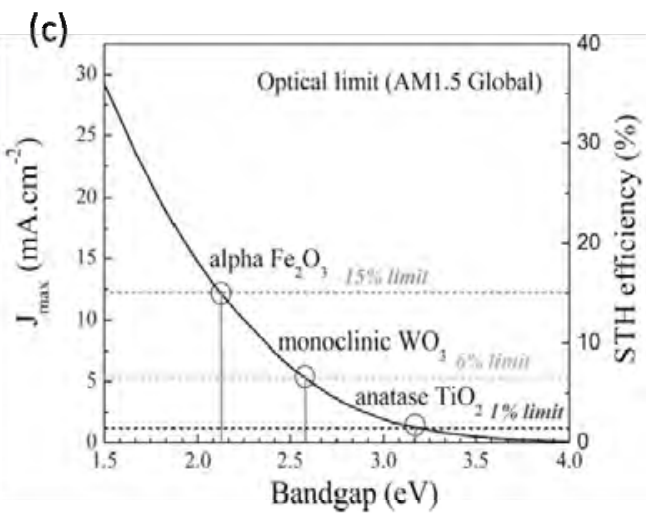

Fig. 1. (a) The relationship between the redox potential and band position on an n-type semiconductor. (b) The difference between observed current-potential curve and theoretical calculation based on Eq. (1). Adapted with permission from Ref. [15]. (c) The theoretical $j$ max and solar-to-hydrogen (STH) efficiency calculated based on the bandgap of semiconductor and sunlight spectrum. Adapted with permission from Ref. [3]. 


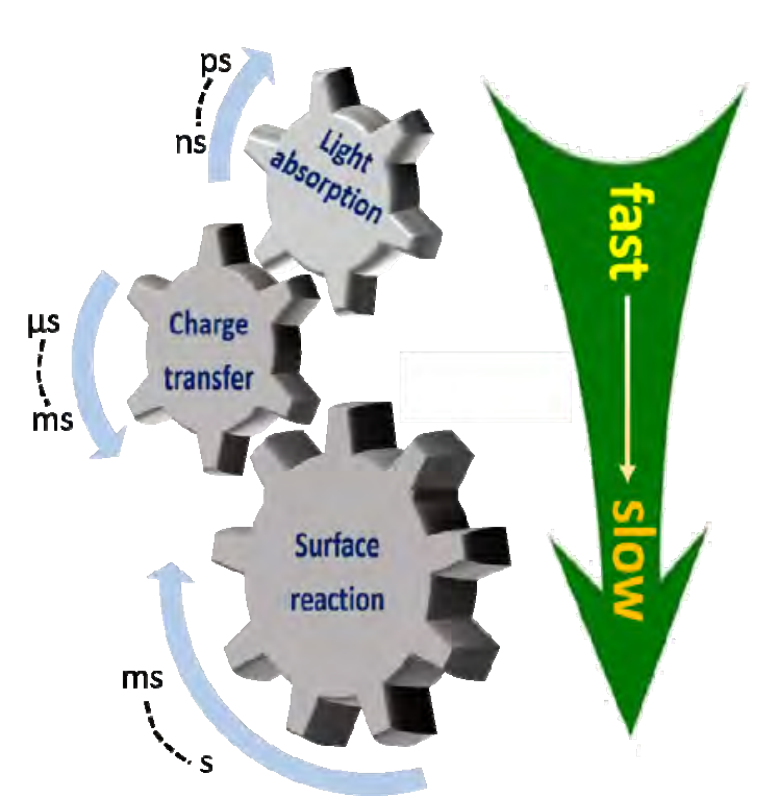

Fig. 2. A schematic illustration of the cooperation between the three criteria during photoelectrochemical process. The time scale of each process is listed for comparison.

match with the ultrafast light absorption process through charge transfer as shown in Fig. 2. Actually, these three parameters have close relationship with the intrinsic property of semiconductors, such as $\alpha, L_{\min }, N_{\mathrm{d}}$ mentioned above. For instance, the light absorbance $(\alpha)$ largely determines the light absorption efficiency ( $\eta_{\text {abs }}$ ). And the charge separation efficiency strongly relies on $L_{\min }$ and $N_{\mathrm{d}}$. Consequently, Eqs. (1) (3) provide us some theoretical guidance towards the de- sign of efficient photoelectrodes.

\section{Light harvesting}

The light harvesting ability determines the utmost photocurrent a semiconductor can achieve. Fig. 1(c) shows the upper limit photocurrent for some intrinsic semiconductor under the $100 \mathrm{~mW} \mathrm{~cm}^{-1}$ sunlight (AM $1.5 \mathrm{G}$ ). It can be improved by expanding the light harvest range or fabricating special texture to capture photons efficiently.

For semiconductors with wide band gap (e.g. $\mathrm{TiO}_{2}, \mathrm{ZnO}$ ), they can only absorb ultraviolent light which only takes $4 \%$ of the whole sunlight spectrum. And the PEC performance is usually limited by their low light harvest capability. Doping is a good choice to broaden the light harvesting. Some N doped $\mathrm{TiO}_{2}$ photoanodes have been reported to expand the light absorption and result in improved photocurrent [21-23]. Buddie et al. [22,23] reported that the photoresponse threshold can be moved to 520 from $420 \mathrm{~nm}$ after nitrogen doping (Fig. 3(a)). But to realize efficient doping of the electrode is not as facile as that is for powder since the conductive substrate should be taken into consideration. The normally used fluorine doped tin oxide (FTO) glass cannot stand high temperature $\left(<600{ }^{\circ} \mathrm{C}\right)$ and strong reductive atmosphere, while the metal substrate cannot bear an oxidative condition. This limits the application of doping strategy in PEC research and some moderate strategies to enlarge the light harvest range have been explored.

Quantum dots have been reported to contribute to the improved light utilization. Carbone quantum dot has the upconversion ability which can converse the low energy photon to high energy one (Fig. 3(b)). It will allow the semiconductor (a)

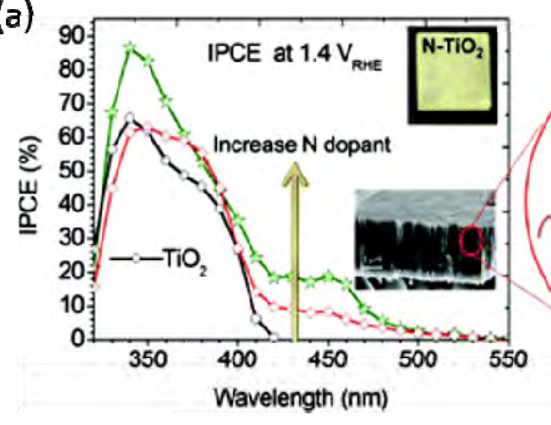

(b)

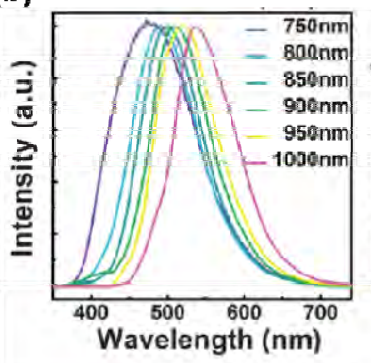

(c)

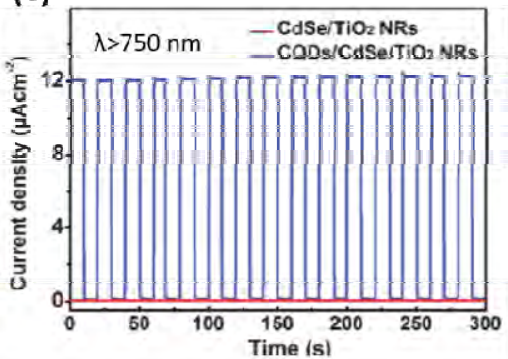

(d)
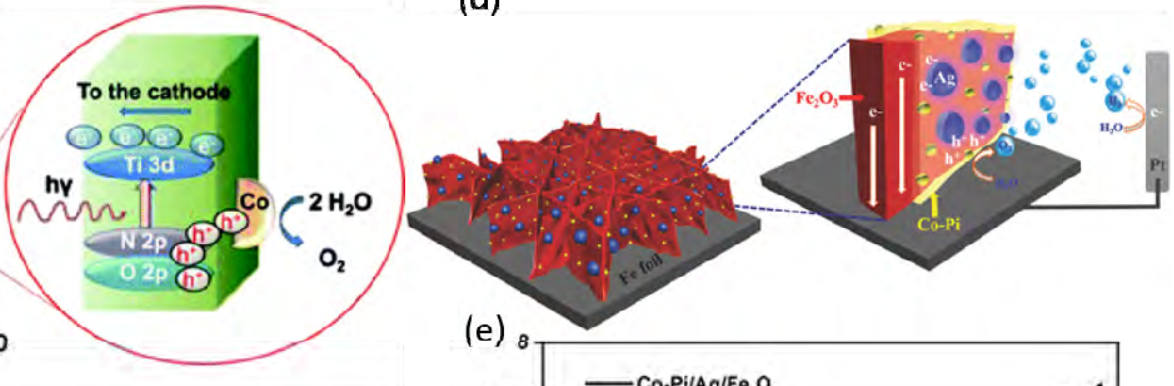

(e)

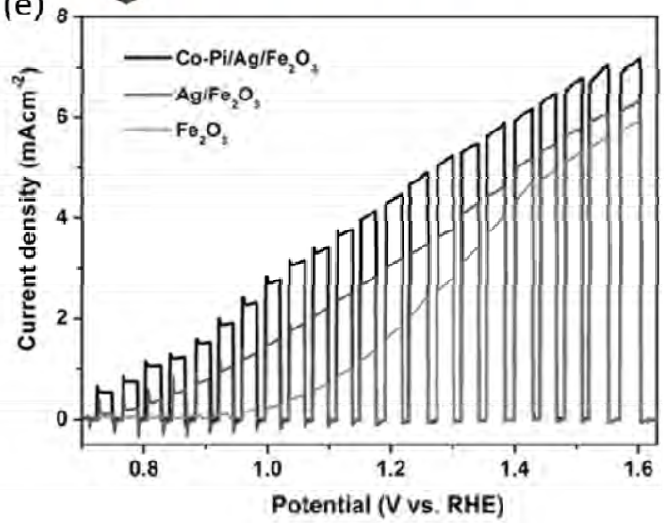

Fig. 3. (a) The influence of Nitrogen doping on the IPCE (left) and band structure (right) of $\mathrm{TiO}_{2}$ photoanode. Adapted with permission from Ref. [23]. (b) The upconversion photoluminescence of carbon quantum dot (CQD). (c) The influence of CQD on the photocurrent under the illumination with wavelength over $750 \mathrm{~nm}$. Adapted with permission from Ref. [26]. (d, e) The scheme and photocurrent of $\mathrm{CoPi} / \mathrm{Ag} / \mathrm{Fe}_{2} \mathrm{O}_{3}$ photoanode. Adapted with permission from Ref. [27]. 
using the light beyond its absorption [24]. Li et al. [25] reported that the graphene quantum dot (GQD) can be used as a green sensitizer to functionalize the $\mathrm{ZnO}$ nanowire photoelectrode. And the induced photon-to-current efficiency (IPCE) curves showed the enhanced light harvest from GQD. Kang et al. [26] reported that carbon quantum dot (CQD) can serve as spectral converter to realize near-infrared light (over $750 \mathrm{~nm}$ ) driven PEC process on $\mathrm{CQD} / \mathrm{CdSe} / \mathrm{TiO}_{2}$ photoanode (Fig. 3(c)). Coin metals such as gold, silver and copper possess strong absorption in the visible spectrum due to localized surface plasmonic resonance (LSPR). They have been used as photosensitizers to improve the PEC water splitting by transferring some of the absorbed plasmonic energy to adjacent semiconductor either through resonant energy transfer or directly hot-electron injection. Peerakiathajohn et al. have shown the prominent contribution of plasmonic effect of Au and Ag particles for PEC water reduction and water oxidation, respectively [27-29]. It shows the photocurrent of $\mathrm{Fe}_{2} \mathrm{O}_{3}$ has over $1 \mathrm{~mA} \mathrm{~cm}^{-2}$ increase after enhancing by the SPR effect from Ag particles (Fig. 3(d) and (e)).

Fabricating electrode with special texture structure is another choice for harvesting light as shown in Fig. 4(a), especially for the semiconductor with low light absorption coefficient [30]. Taking $\mathrm{Fe}_{2} \mathrm{O}_{3}$ for example, it is an in-direct band gap semiconductor with low light absorption ability [31] . By improving the film thickness, the light harvest can be enhanced. But as a tradeoff, the photogenerated charges should penetrate a long pathway which will promote the charge recombination as well.
Recently, Yang et al. [32,33] reported a novel $\mathrm{Fe}_{2} \mathrm{O}_{3}$ photoanode with ultrathin film deposited on three-dimensional nanophotonic structures (Fig. 4(b)), such as nanospike, nanocone. The 3D structure guarantees the full utilization of light and small thickness guarantees the efficient collection of photocharges. Cui et al. [34] also demonstrated that $\mathrm{BiVO}_{4}$ film with a nanocone (Fig. 4(c)) structure had much better performance than the platform one. However, for electrodes with high aspect ratio, increasing the roughness can also result in significantly improved surface area. A convinced influence of light harvest can be concluded only when the impact of surface area is ruled out.

\section{Charge separation}

The charge separation in the photoelectrode is critical for the following surface reaction. Only in the space charge layer can the photo excited electron-hole (e-h) pairs be segregated effectively (Fig. 1(a)). The e-h pairs generated in the bulk can also be separated if they can diffuse into the space charge layer. And for the separated charges, they should be collected by the substrate or consumed within their lifetime. Otherwise a surface state induced recombination or backward recombination will happen (Fig. 5(a)) [35,36]. Indeed, the apparent charge separation efficiency of a photoelectrode is determined by both the charge generation efficiency in the crystals and the charge transfer efficiency among the crystals (Fig. 5(b)) [37]. And most of the reported strategies try to address these two criteria to
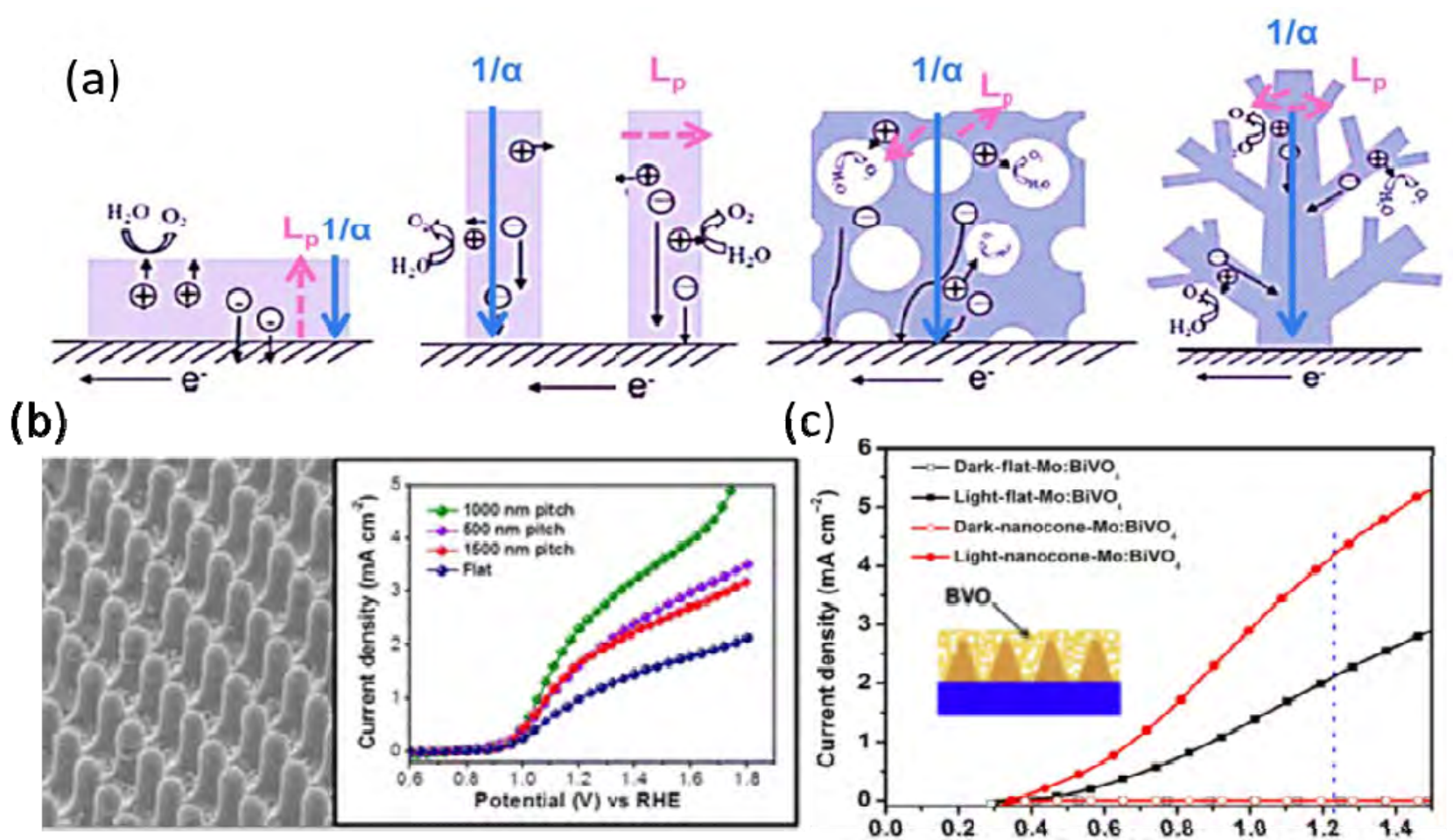

(c)

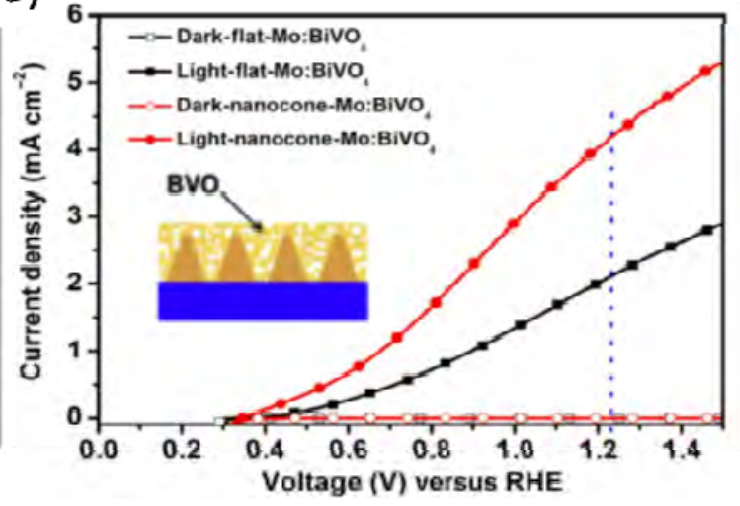

Fig. 4. (a) The comparison of charge transfer on the electrodes with different structure, including, plate, 1D structure, 3D porous structure and dendrite structure. Adapted with permission from Ref. [30]. (b) The morphology of nanophotonic $\mathrm{Fe}_{2} \mathrm{O}_{3}$ nanospike and its photocurrent. Adapted with permission from Ref. [33]. (c) The comparison of photocurrent between the flat and nanocone $\mathrm{Mo:BiVO}_{4}$ photoanode. Adapted with permission from Ref. [34]. 

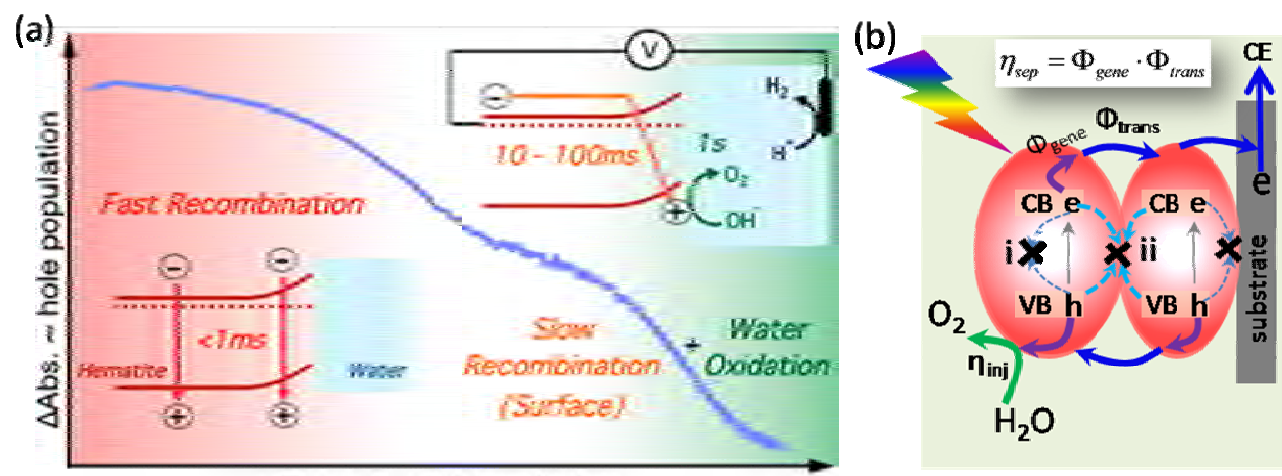

Time after light excitation

Fig. 5. (a) Different charge recombination process, including direct charge (fast) recombination and back (surface) recombination on hematite photoanode. Adapted with permission from Ref. [35]. (b) The schematic illustration of the PEC water oxidation processes, including charge generation in the particles, charge transfer among particles and charge collection by substrate and reaction on surface. The apparent charge separation efficiency $\left(\eta_{\text {sep }}\right)$ is determined by charge generation $\left(\Phi_{\text {gene }}\right)$ in particles and charge transfer $\left(\Phi_{\text {trans }}\right)$ among particles. Adapted with permission from Ref. [37].

improve the charge separation of the photoelectrodes.

Surface sites are the major sites for the recombination of photo charges. Therefore, passivating the surface states will always lead to improved charge separation. In Si based solar conversion process, a $\mathrm{TiO}_{2}$ passivation layer is always necessary to trig the photoresponse. Similar effect has been reported in $\mathrm{Al}_{2} \mathrm{O}_{3}$ or $\mathrm{Ga}_{2} \mathrm{O}_{3}$ passivated hematite photoanodes [38,39]. The cobalt phosphate (CoPi) which is traditionally viewed as cocatalyst has also been suggested to have the capability to depress the surface states of $\mathrm{BiVO}_{4}$ and promote the charge separation efficiency [40]. Although surface states play a critical role in photoelectrochemistry, a convinced evidence to confirm the existence of surface state is very important when we attempt to attribute the impact from surface states. However, it is not an easy work to identify them and some attempts can be referred to Refs. [41-43].

Improving the charge transfer in the electrode can also enhance the charge separation. Built-in field created by p-n junction or heterojunction will provide efficient driving force to facilitate charge transfer, resulting in much more effective charge separation in the photoelectrode. For example, $\mathrm{WO}_{3}$ and $\mathrm{BiVO}_{4}$ can form a well-matched heterojunction which will pro- duce a much higher water oxidation rate than single $\mathrm{BiVO}_{4}$ photoanode [44]. And CdS has been demonstrated to form p-n junction with kinds of p-type sulfide semiconductor (e.g. CuInS 2 [45], $\mathrm{Cu}_{2} \mathrm{ZnSnS}_{4}$ [46]) so as to promote the transfer of photoelectrons.

Besides forming built-in field, eliminating the crystal boundaries can also improve the charge transfer in the films. For a photoelectrode, the most profound boundary exists at the interfaces between semiconductors and the substrate (e.g. FTO, metal). The ideal way to deal with this problem is to epitaxial deposit the film on the substrate. But only a few candidates can grow directly on the substrate and many efficient photocatalyst particles cannot form effective photoelectrode due to poor connection at the substrate/semiconductor and particle-particle interfaces. Zou et al. [47] showed that $\mathrm{LaTiO}_{2} \mathrm{~N}$ photoelectrodes fabricated with large particles was outperformed that with small particles since there would be more crystal boundary to impede the charge transfer among small particles. Domen's group reported a particle transfer method which could prepare photoelectrode from powder photocatlyst in a bottom up way (Fig. 6). The particles building ohmic contact with the sputtered metal is scratched off to form a sin-
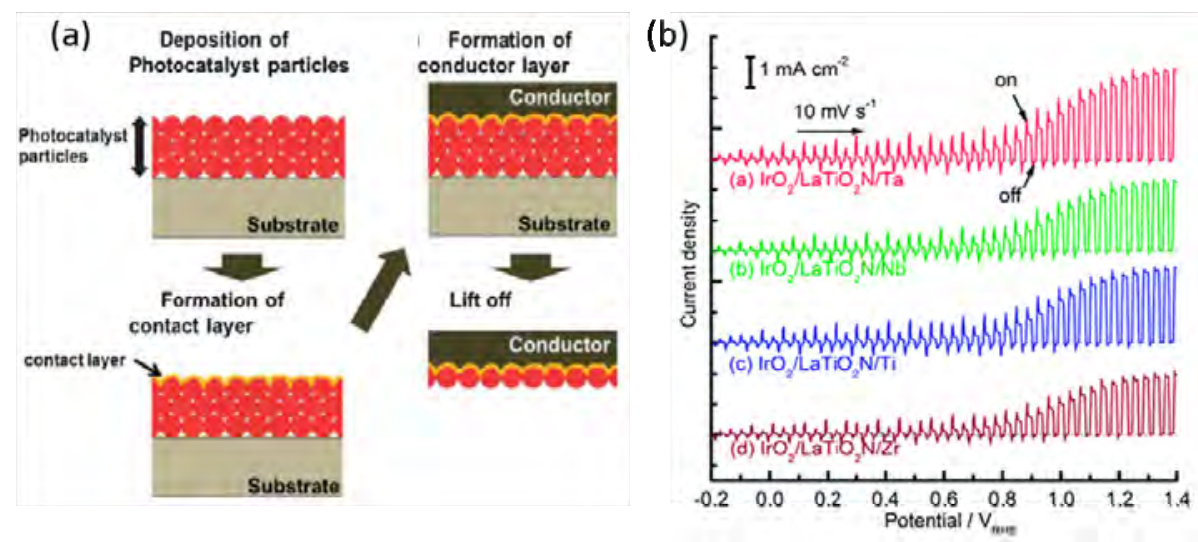

Fig. 6. (a) The schematic process of particle transfer method. (b) The PEC performance of LaTiO ${ }_{2} \mathrm{~N}$ photoanode prepared by particle transfer method with different underlayer metal. Adapted with permission from Ref. [50]. 
gle-crystal layer photoelectrode. It is an effective method in fabricating $\mathrm{BiVO}_{4}$ [48], $\mathrm{BaTaO}_{2} \mathrm{~N}$ [49], $\mathrm{LaTiO}_{2} \mathrm{~N}$ [50], $\mathrm{La}_{5} \mathrm{Ti}_{2} \mathrm{CuS}_{5} \mathrm{O}_{7}$ [51] photoelectrode. However, it is sensitive to the contacted metal and particle sizes. Some other technologies also can be used to fabricate photoelectrode in a bottom up way. Pulsed laser deposition can be used to deposit as-prepared photocatalyst on different kinds of substrates. But strong internal stress will leads to weak charge separation $[52,53]$. Electrophoresis process can also deposit photocatalyst onto conductive substrate. And a following necking treatment can release the resistance originated from grain boundary. And many (oxy)nitride photoanodes have fabricated in this method $[37,54,55]$.

Doping is also reported to improve the charge separation efficiency. In hematite photoanode, Ti, Sn and Pt etc. have been proven to facilitate the charge separation $[20,56]$. And Mo or W doped $\mathrm{BiVO}_{4}$ also have shown better charge separation than pure one [57,58]. Wang et al. [59] recently reported oxygen vacancies could work as dopant in promoting the PEC performance of $\mathrm{BiVO}_{4}$ greatly (Fig. 7(a)). Notwithstanding of those examples, based on Eqs. (1) and (3), a large carrier concentration seems to have a negative influence on the photoresponse since it will lead to a narrow space charge layer and create more recombination centers. Yet, practically, doping can greatly improve the conductivity in the semiconductor film and increase the electric field in the space charge layer. As a result, a much more facial charge transfer is expected in doped photoelectrode.

\section{Surface charge reaction}

Surface reaction is the last step towards sunlight utilization and it relies heavily on the surface property of the semiconductor. Different semiconductors show different surface catalytic ability. For instance, the surfaces of $\mathrm{TiO}_{2}$ and $\mathrm{WO}_{3}$ have been reported to be highly active towards water oxidation [60], so these two kinds of photoelectrodes seldom need cocatalyst to assist the surface reaction. But most other semiconductors require additional cocatalysts to improve their surface reaction kinetics and $\mathrm{Ta}_{3} \mathrm{~N}_{5}$ is a typical example. Due to its hydrophobic surface property [61], raw $\mathrm{Ta}_{3} \mathrm{~N}_{5}$ shows weak photocurrent. After loading cocatalyst, e.g., $\mathrm{CoPi}$ [37] or $\mathrm{Co}_{3} \mathrm{O}_{4}$ [8], to promote the surface reaction, its photocurrent can be doubled. Especially, Liu et al. [62] reported that after loading a hybrid cocatalyst, $\mathrm{NiOOH} /$ Ferrihydrite (Fh) and Ir and Co molecular catalyst on $\mathrm{Ta}_{3} \mathrm{~N}_{5}$ photoanode, its photocurrent could approach the theoretical $12.6 \mathrm{~mA} \mathrm{~cm}^{-2}$ under $100 \mathrm{~mW} \mathrm{~cm}^{-2}$ simulated sunlight (Fig. 7(d)).

Due to the blur water splitting mechanism on cocatalyst, it is still a trial-and-error process to explore new and efficient cocatalyst for matching with the semiconductor electrode. The $\mathrm{Ni}$, Co, and Fe based oxide, [63] layer double hydroxide (LDH) (a)

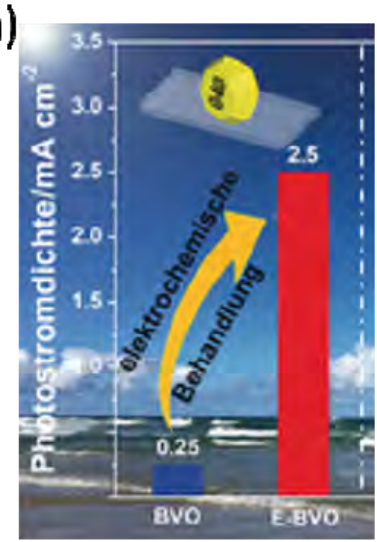

(d)

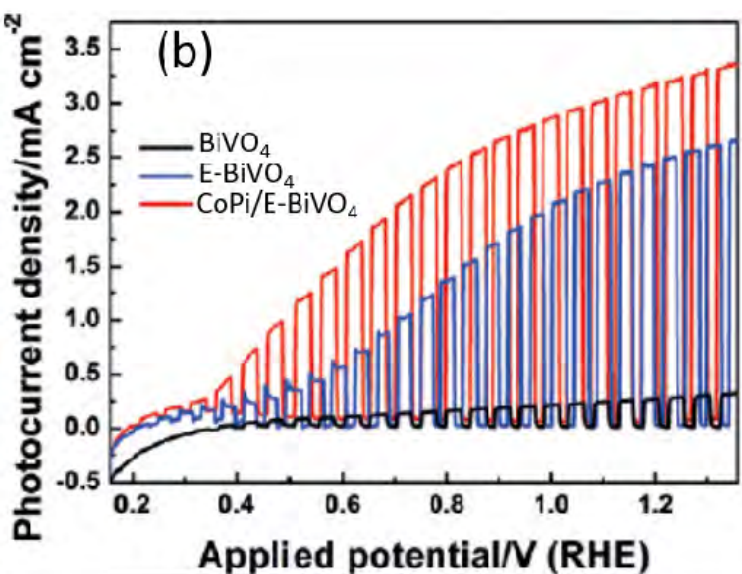

(c)

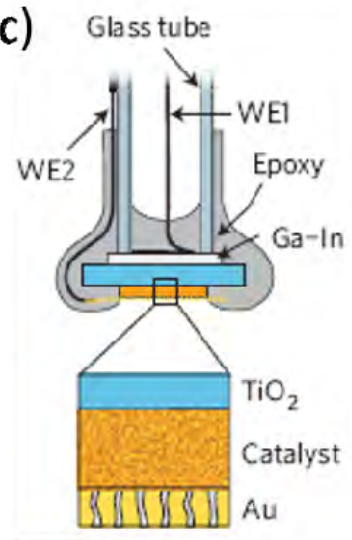

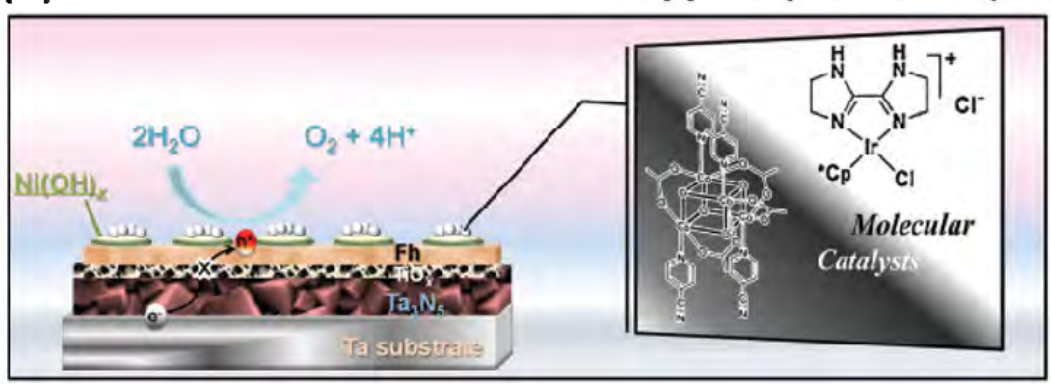

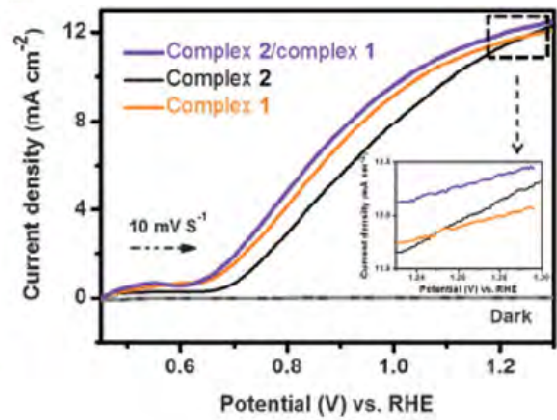

Fig. 7. (a, b) The photocurrent increasing after electrochemical treatment and loading CoPi as cocatalyst. Adapted with permission from Ref. [59]. (c) The diagram of dual working electrode for the measurement of the potential distribution in semiconductor $\left(\mathrm{TiO}_{2}\right)$ and cocatalyst. Adapted with permission from Ref. [69]. (d) The schematic illustration of integrated photoanode of $\mathrm{Ta}_{3} \mathrm{~N}_{5} / \mathrm{TiO}_{2} / \mathrm{Fh} / \mathrm{Ni}(\mathrm{OH})_{x} / \mathrm{Ir}$, Co complex and its photoresponse. Adapted with permission from Ref. [62]. 
$[64,65]$, phosphate [59] or phosphide [66] are the most frequently adopted cocatalyst in photoanode for water oxidation, and Pt [67], Ni-Mo alloy [68] in photocathode for water reduction. Basically, only the material with considerable electrocatalytic ability will have the potential in using as cocatalyst. But their electrocatalytic capability (taking the overpotential and Tafel slope as figure of merits) does not necessary determine their performance in PEC process. For example, $\mathrm{RuO}_{2}$ and $\mathrm{Pt}$ outperform CoPi in water oxidation, but the latter has more profound impact in enhancing the oxygen evolution reaction on such as $\mathrm{BiVO}_{4}, \mathrm{Ta}_{3} \mathrm{~N}_{5}$ photoanodes. And the cocatalyst should match with the photocatalyst so as to maximize the photocurrent. Some pioneer researches from Boettcher group shed light on the choice of cocatalyst [69-71]. They designed a dual work electrode test system (Fig. 7(c)) to determine the potential change in semiconductor and cocatalyst respectively, and found that the ionic permeable cocatalyst (e.g. $\mathrm{NiOOH}$ ) can form an adaptive Schottky junction with the semiconductor, resulting in more efficient semiconductor-catalyst charge transfer compared to the case in dense cocatalyst (e.g. $\mathrm{IrO}_{2}$ ) where a buried junction with constant Schottky barrier is formed [69].

In principle, the cocatalyst participates in the charge capture from the semiconductor and charge consumption by water electrolysis via a series of redox coupling process. As long as we can determine the redox potential of the intermediate, we can design the expected cocatalyst. But it is always not an easy work since the catalyst surface will change and an amorphous or weak crystallized layer often lead to reconstruction of the cocatalyst. More researches are appealed to match the gaps between the cocatalyst and photoelectrode.

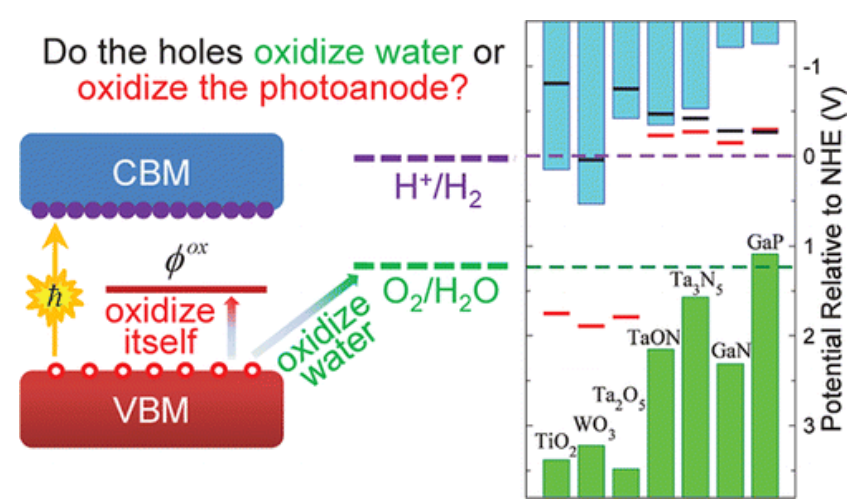

Fig. 8. The relationship between band edge position and self-oxidized potential for photoanode. Adapted with permission from Ref. [72].

\section{Stability}

Stability plays an equally important role for the photoelectrode design. Many promising photoelectrodes face the problem of longtime stability, e.g., $\mathrm{Si}, \mathrm{Cu}_{2} \mathrm{O}$. In this regard, researchers eventually try to achieve a higher stability at the cost of losing some efficiency for practical application. There are two categories of corrosion, chemical corrosion and electrochemical corrosion, leading to the failure of photoelectrodes. For chemical corrosion, it is due to the chemical dissolution of the semiconductor in the electrolyte. For instance, $\mathrm{WO}_{3}$ will decompose in the solution with $\mathrm{pH}>5$ and $\mathrm{ZnO}$ can only stably exist in neutralized solution. The Pourbaix diagram can be referred to so as to avoid this kind of corrosion. For the electrochemical corrosion, it happens when the surface photocharges are consumed at a low rate and the thermodynamically oxidative (reductive) potential of the semiconductor is lower (higher) than
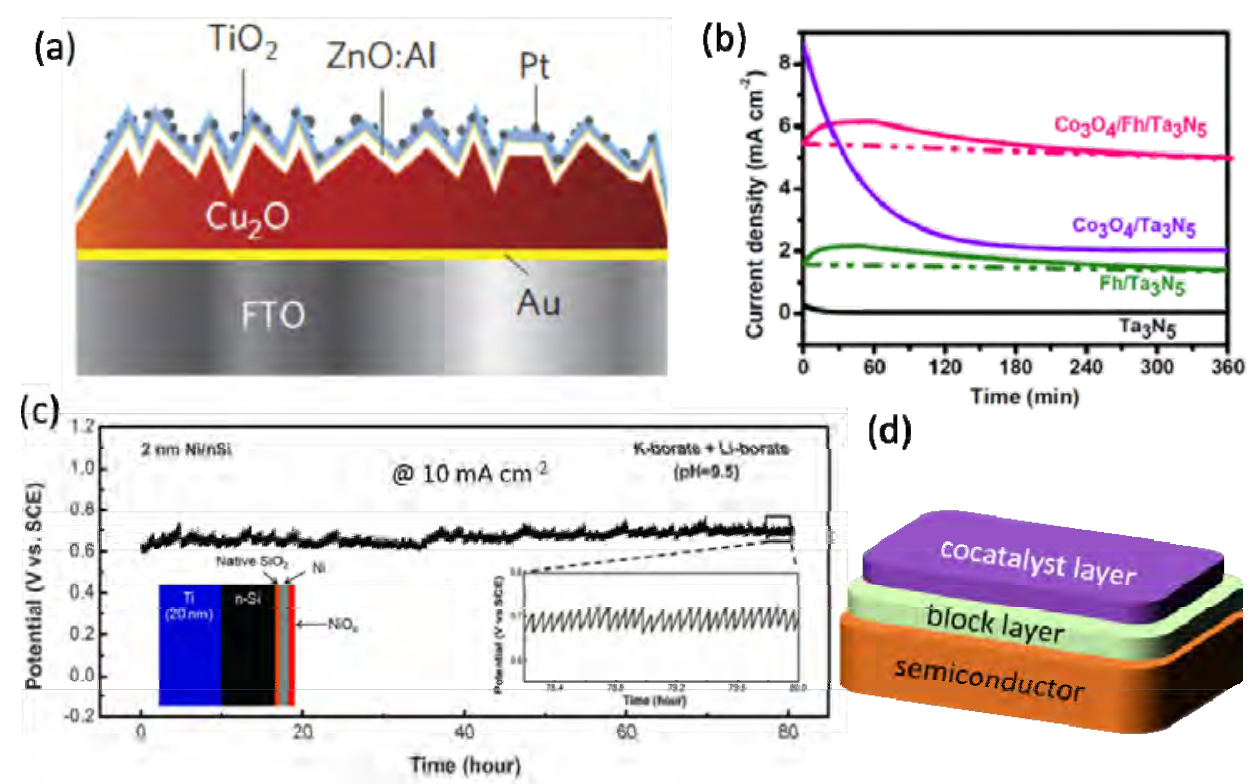

(d)

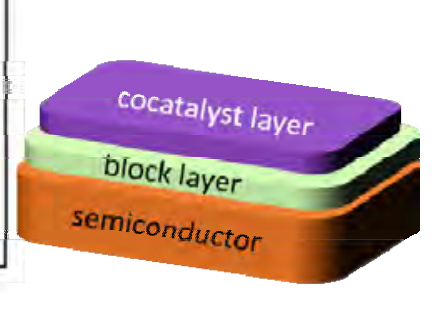

Fig. 9. (a) The diagram of $\mathrm{Cu}_{2} \mathrm{O}$ photocathode modified with compact $\mathrm{TiO}_{2}$ layer and Pt cocatalyst particles. Adapted with permission from Ref. [73]. (b) The influence of ferrihydrite (Fh) on the stability of $\mathrm{Ta}_{3} \mathrm{~N}_{5}$ photoanode during water oxidation. Adapted with permission from Ref. [8]. (c) The stability of Si photoanode (@ $10 \mathrm{~mA} \mathrm{~cm}{ }^{-2}$ ) in potassium borate solution containing Li ions after modifying with $2 \mathrm{~nm}$ Ni. Adapted with permission from Ref. [75]. (d) The schematic illustration of semiconductor|block layer|cocatalyst layer design. 
water oxidation (reduction) potential. In this case, the unconsumed electrons or holes will react with the semiconductor itself, leading to a self-corrosion (Fig. 8) [72].

In order to inhibit the unfavored process, the photoelectrode is expected to separate from the electrolyte along with accelerating the surface photocharge consumption rate. Depositing a pin-hole free layer (usually metal oxide, e.g. $\mathrm{Al}_{2} \mathrm{O}_{3}, \mathrm{TiO}_{2}$ ) on the photoelectrode can avoid the direct contact between photoelectrode and electrolyte. Paracchino et al. [73] reported that the stability of $\mathrm{Cu}_{2} \mathrm{O}$ photocathode can be prolonged by deposition a $\mathrm{TiO}_{2}$ compact layer and decorating with Pt (Fig. 9(a)). Liu et al. [8] reported that after modifying $\mathrm{Ta}_{3} \mathrm{~N}_{5}$ with a thick hole storage layer (e.g., ferrihydrite) to draw the photogenerated holes away, the $\mathrm{Ta}_{3} \mathrm{~N}_{5}$ can stably photocatalyze water oxidation for over $6 \mathrm{~h}$ (Fig. 9(b)). Due to the thermodynamical instability of $\mathrm{Cu}_{2} \mathrm{O}$ [73], $\mathrm{Ta}_{3} \mathrm{~N}_{5}$ [8] and $\mathrm{Si}$ [74] in the presence of water, the only way to prevent them from being corroded is to deposit a block layer to separate the semiconductor form the solution. Yet, this layer is usually in low catalytic capability, another cocatalyst layer is necessary. This kind of semiconductor|block layer|cocatalyst layer design (Fig. 9(d)) can be a promising routine to stabilize the narrow bandgap semiconductor photoelectrode. Additionally, Dai et al. [75] reported that the stability of $\mathrm{Ni} / \mathrm{TiO}_{2} / \mathrm{Si}$ photoanode was much better after adding $\mathrm{Li}^{+}$ions into the electrolyte, emphasizing the importance of composition of electrolyte on stability (Fig. 9(c)).

\section{Summary and outlook}

With over four decades of intensive research efforts, the field of PEC water splitting has a profound progress in terms of material and electrode design, efficiency and stability. The applied bias photon-to-current efficiency (ABPE) has reached approximate $3 \%$ for a single photoelectrode [76]. However, when taking stability and cost into consideration, we are still just at the beginning of the long journey. And also, most of the PEC systems are single photoelectrode system without capability to realize an unbiased solar-to-hydrogen conversion. For dual-photoelelctrode system (photoanode-photocathode), although the spontaneous water splitting systems have been reported, the efficiency is still below $1 \%[77,78]$.

In order to achieving more effective solar hydrogen production, we should take the light harvest, charge separation and surface reaction into an integral consideration. The rate-determined steps (RDS) should be carefully analyzed so as to reform the photoelectrode. Taking the $\mathrm{Fe}_{2} \mathrm{O}_{3}$ and $\mathrm{Ta}_{3} \mathrm{~N}_{5}$ for examples, the $\mathrm{RDS}$ in $\mathrm{Fe}_{2} \mathrm{O}_{3}$ photoanode is charge separation but for $\mathrm{Ta}_{3} \mathrm{~N}_{5}$ it is surface reaction. So for $\mathrm{Fe}_{2} \mathrm{O}_{3}$ based research, more efforts are focused on improving the charge generation but for $\mathrm{Ta}_{3} \mathrm{~N}_{5}$ based research, more attentions are paid on optimizing the surface charge injection. Furthermore, when loading cocatalyst on the surface of photoelectrode, some light will be shielded off, resulting in decreased light harvest efficiency. When expanding the light harvest through energy band modification, the oxidative (reductive) capability of holes (electrons) will be weakened, resulting in a possible sluggish surface reaction. We should try to balance each step.
It is worth noting that a tandem PV-PEC or PV-EC system also deserves attention in solar conversion [79]. The reported solar-to-hydrogen (STH) efficiency can be as high as $22 \%$ for GaInP/GaAs/Ge multi-junction solar cell combined PEC system [80]. Recently, the breakthrough in perovskite solar cell (PSC) also boosts the STH conversion. By combining a PSC with NiFe LDH for water electrolysis, Luo et al. demonstrated $12.3 \%$ solar conversion efficiency [81]. But this PV-EC system needs a large bias (usually over $1.5 \mathrm{~V}$ ) which can only be provided by multijunction solar cell. It will complicate the system and increase the total cost, and the stability of PSC is also a concern. By directly conjugating with $\mathrm{BiVO}_{4}$ photoanodes, only one PSC can achieve an STH of $4.3 \%$ [82]. Although this structure is much simpler, there is great loss of the energy comparing with the over 15\% efficiency of PSC [82]. The major limitation still lies in the photoelectrodes where the current-potential $(j-V)$ curves usually have a large onset potential or low photocurrent, leading to a work point bias from the solar cell's maximum power output point.

Designing efficient photoelectrode is a systematic engineering relating to materials, photochemistry, electrochemistry and catalysis. In terms of materials, it is the fundamental of photoelectrochemistry and many visible and even near infra-red semiconductor candidates have been explored which provide more candidates for the electrode design. At the heart of the photoelectrochemistry is charge transfer at different kinds of interfaces in a substrate|semiconductor|cocatalyst|electrolyte system. And the surface reaction is the determinable step towards photon energy conversion. It is critically vital to analyze the bottleneck steps for charge transfer in both experimental and theoretical ways. With deep understanding on the fundamental and working mechanisms of the PEC process, we will be able to efficiently convert abundant solar energy into clean solar fuel, thus addressing the global energy and environmental challenges.

\section{Acknowledgments}

The Queensland node of the Australian National Fabrication Facility is also appreciated.

\section{References}

[1] B. Kumar, M. Llorente, J. Froehlich, T. Dang, A. Sathrum, C. P. Kubiak, Annu. Rev. Rhys. Chem., 2012, 63, 541-569.

[2] M. G. Walter, E. L. Warren, J. R. McKone, S. W. Boettcher, Q. Mi, E. A. Santori, N. S. Lewis, Chem. Rev., 2010, 110, 6446-6473.

[3] Z. B. Chen, T. F. Jaramillo, T. G. Deutsch, A. Kleiman-Shwarsctein, A. J. Forman, N. Gaillard, R. Garland, K. Takanabe, C. Heske, M. Sunkara, E. W. McFarland, K. Domen, E. L. Miller, J. A. Turner, H. N. Dinh, J. Mater. Res., 2010, 25, 3-16.

[4] M. Gratzel, Nature, 2001, 414, 338.

[5] A. Fujishima, K. Honda, Nature, 1972, 238, 37-38.

[6] R. Shinar, J. H. Kennedy, Sol. Energy Mater., 1982, 6, 323-335.

[7] C. Zhen, L. Wang, G. Liu, G. Q. M. Lu, H. M. Cheng, Chem. Comm. 2013, 49, 3019-3021.

[8] G. J. Liu, J. Y. Shi, F. X. Zhang, Z. Chen, J. F. Han, C. M. Ding, S. S. Chen, Z. L. Wang, H. X. Han, C. Li, Angew. Chem. Int. Ed., 2014, 53, 


\section{Graphical Abstract}

Chin. J. Catal., 2018, 39: 369-378 doi: 10.1016/S1872-2067(17)62998-X

\section{Progress in designing effective photoelectrodes for solar water splitting}

Zhiliang Wang, Lianzhou Wang*

University of Queensland, Australian

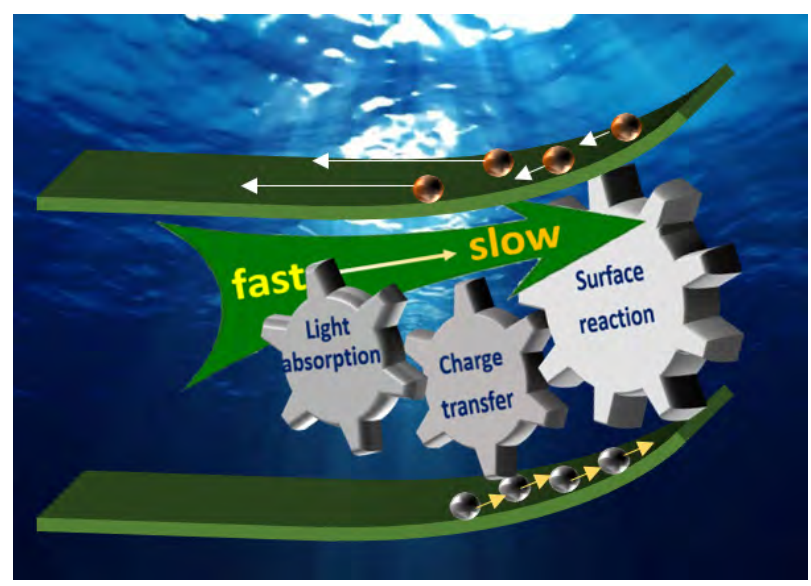

Three key steps, including light absorption, charge transfer and surface reaction with huge time scale difference of individual steps in photoelectrochemical water splitting process, should be considered integrally for efficient photoelectrode design.

7295-7299.

[9] Z. L. Wang, J. F. Han, Z. Li, M. R. Li, H. Wang, X. Zong, C. Li, Adv. Energy Mater, ,2016, 6, 1600864.

[10] K. P. Sokol, D. Mersch, V. Hartmann, J. Z. Zhang, M. M. Nowaczyk, M. Rögner, A. Ruff, W. Schuhmann, N. Plumeré, E. Reisner, Energy Environ. Sci., 2016, 9, 3698-3709.

[11] Z. Yu, F. Li, L. C. Sun, Energy Environ. Sci., 2015, 8, 760-775.

[12] A. J. Bard, M. A. Fox, Acc. Chem. Res., 1995, 28, 141-145.

[13] K. Sivula, Chimia, 2013, 67, 155-161.

[14] Z. Zhang, J. T. Yates Jr, Chem. Rev., 2012, 112, 5520-5551.

[15] R. H. Wilson, Crit. Rev. Solid State and Mater. Sci., 1980, 10, 1-41.

[16] H. Gerischer, Electrochi. Acta, 1990, 35, 1677-1699.

[17] H. Gerischer, in: Photovoltaic and photoelectrochemical solar energy conversion, Springer, 1981, 199-261.

[18] S. Soedergren, A. Hagfeldt, J. Olsson, S. E. Lindquist, J. Phys. Chem., 1994, 98, 5552-5556.

[19] H. Dotan, K. Sivula, M. Grätzel, A. Rothschild, S. C. Warren, Energy Environ. Sci., 2011, 4, 958-964.

[20] Z. L. Wang, G. J. Liu, C. M. Ding, Z. Chen, F. X. Zhang, J. Y. Shi, C. Li, J. Phys. Chem. C, 2015, 119, 19607-19612.

[21] G. M. Wang, X. H. Xiao, W. Q. Li, Z. Y. Lin, Z. P. Zhao, C. Chen, C. Wang, Y. J. Li, X. Q. Huang, L. Miao, C. Z. Jiang, Y. Huang, X. F. Duan, Nano Lett., 2015, 15, 4692-4698.

[22] S. Hoang, S. P. Berglund, N. T. Hahn, A. J. Bard, C. B. Mullins, J. Am. Chem. Soc., 2012, 134, 3659-3662.

[23] S. Hoang, S. W. Guo, N. T. Hahn, A. J. Bard, C. B. Mullins, Nano Lett., 2011, 12, 26-32.

[24] S. J. Zhuo, M. W. Shao, S. T. Lee, ACS Nano, 2012, 6, 1059-1064.

[25] C. X. Guo, Y. Q. Dong, H. B. Yang, C. M. Li, Adv. Energy Mater, 2013, 3, 997-1003.

[26] X. Zhang, H. Huang, J. Liu, Y. Liu, Z. H. Kang, J. Mater. Chem. A, 2013, 1,11529-11533.

[27] P. Peerakiatkhajohn, J. H. Yun, H. Chen, M. Lyu, T. Butburee, L. Wang, Adv. Mater., 2016, 28, 6405-6410.

[28] H. J. Chen, Q. Wang, M. Q. Lyu, Z. Zhang, L. Z. Wang, Chem. Comm.,
2015, 51, 12072-12075.

[29] P. Peerakiatkhajohn, T. Butburee, J. H. Yun, H. J. Chen, R. M. Richards, L. Z. Wang, J. Mater. Chem. A, 2015, 3, 20127-20133.

[30] P. Zhang, L. Gao, X. F. Song, J. Sun, Adv. Mater., 2015, 27, 562-568.

[31] K. Sivula, F. Le Formal, M. Grätzel, ChemSusChem, 2011, 4, 432-449.

[32] J. K. Li, Y. C. Qiu, Z. H. Wei, Q. F. Lin, Q. P. Zhang, K. Y. Yan, H. N. Chen, S. Xiao, Z. Y. Fan, S. H. Yang, Energy Environ. Sci., 2014, 7, 3651-3658.

[33] Y. C. Qiu, S. F. Leung, Q. P. Zhang, B. Hua, Q. F. Lin, Z. H. Wei, K. H. Tsui, Y. G. Zhang, S. H. Yang, Z. Y. Fan, Nano Lett., 2014, 14, 2123-2129.

[34] Y. C. Qiu, W. Liu, W. Chen, G. M. Zhou, P. C. Hsu, R. F. Zhang, Z. Liang, S. S. Fan, Y. G. Zhang, Y. Cui, Sci. Adv., 2016, 2, e1501764.

[35] F. Le Formal, S. R. Pendlebury, M. Cornuz, S. D. Tilley, M. Grätzel, J. R. Durrant, J. Am. Chem. Soc., 2014, 136, 2564-2574.

[36] R. Liu, Z. Zheng, J. Spurgeon, X. G. Yang, Energy Environ. Sci., 2014, 7, 2504-2517.

[37] Z. L. Wang, Y. Qi, C. M. Ding, D. Y. Fan, G. J. Liu, Y. L. Zhao, C. Li, Chem. Sci,. 2016, 7, 4391-4399.

[38] F. Le Formal, N. Tétreault, M. Cornuz, T. Moehl, M. Grätzel, K. Sivula, Chem. Sci., 2011, 2, 737-743.

[39] T. Hisatomi, F. Le Formal, M. Cornuz, J. Brillet, N. Tétreault, K. Sivula, M. Grätzel, Energy Environ. Sci., 2011, 4, 2512-2515.

[40] C. Zachäus, F. F. Abdi, L. M. Peter, R. van de Krol, Chem. Sci., 2017, 8, 3712-3719.

[41] B. Klahr, T. Hamann, J. Phys. Chem. C, 2014, 118, 10393-10399.

[42] O. Zandi, T. W. Hamann, Nat. Chem., 2016, 8, 778-783.

[43] Z. L. Wang, F. T. Fan, S. Y. Wang, C. M. Ding, Y. L. Zhao, C. Li, RSC Adv., 2016, 6, 85582-85586.

[44] Y. Pihosh, K. Mawatari, J. Uemura, Y. Kazoe, T. Kitamori, I. Turkevych, S. Kosar, K. Makita, T. Sugaya, T. Matsui, M. Kondo, D. Fujita, M. Tosa, Sci. Rep., 2015, 5,11141.

[45] J. Zhao, T. Minegishi, L. Zhang, M. Zhong, M. Nakabayashi, G. J. Ma, T. Hisatomi, M. Katayama, S. Ikeda, N. Shibata, T. Yamada, K. 
Domen, Angew. Chem. In. Ed., 2014, 53, 11808-11812.

[46] F. Jiang, Gunawan, T. Harada, Y. Kuang, T. Minegishi, K. Domen, S. Ikeda, J. Am. Chem. Soc., 2015, 137, 13691-13697.

[47] J. Y. Feng, W. J. Luo, T. Fang, H. Lv, Z. Q. Wang, J. Gao, W. M. Liu, T. Yu, Z. S. Li, Z. G. Zou, Adv. Func. Mater., 2014, 24, 3535-3542.

[48] M. Zhong, T. Hisatomi, Y. Kuang, J. Zhao, M. Liu, A. Iwase, Q. Jia, H. Nishiyama, T. Minegishi, M. Nakabayashi, N. Shibata, R. Niishiro, C. Katayama, H. Shibano, M. Katayama, A. Kudo, T. Yamada, K. Domen, J. Am. Chem. Soc., 2015, 137, 5053-5060.

[49] K. Ueda, T. Minegishi, J. Clune, M. Nakabayashi, T. Hisatomi, H. Nishiyama, M. Katayama, N. Shibata, J. Kubota, T. Yamada, K. Domen, J. Am. Chem. Soc., 2015, 137, 2227-2230.

[50] T. Minegishi, N. Nishimura, J. Kubota, K. Domen, Chem. Sci., 2013, 4, 1120-1124.

[51] J. Y. Liu, T. Hisatomi, G. J. Ma, A. Iwanaga, T. Minegishi, Y. Moriya, M. Katayama, J. Kubota, K. Domen, Energy Environ. Sci., 2014, 7, 2239-2242.

[52] J. Y. Cao, T. Kako, N. Kikugawa, J. H. Ye, J. Phy. D, 2010, 43, 325101.

[53] A. V. Moholkar, S. S. Shinde, G. L. Agawane, S. H. Jo, K. Y. Rajpure, P. S. Patil, C. H. Bhosale, J. H. Kim, J. Alloys Compd., 2012, 544, 145-151.

[54] R. Abe, T. Takata, H. Sugihara, K. Domen, Chem. Lett., 2005, 34, 1162-1163.

[55] R. Abe, M. Higashi, K. Domen, J. Am. Chem. Soc., 2010, 132, 11828-11829.

[56] N. T. Hahn, C. B. Mullins, Chem. Mater., 2010, 22, 6474-6482.

[57] C. M. Ding, J. Y. Shi, D. E. Wang, Z. J. Wang, N. Wang, G. J. Liu, F. Q. Xiong, C. Li, Phys. Chem. Chem. Phys., 2013, 15, 4589-4595.

[58] F. F. Abdi, L. Han, A. H. M. Smets, M. Zeman, B. Dam, R. Van De Krol, Nat. Commun., 2013, 4, 2195.

[59] S. C. Wang, P. Chen, J. H. Yun, Y. X. Hu, L. Z. Wang, Angew. Chem. Int. Ed., 2017, 56, 8500-8504.

[60] J. M. Spurgeon, J. M. Velazquez, M. T. McDowell, Phys. Chem. Chem. Phys., 2014, 16, 3623-3631.

[61] S. S. Chen, S. Shen, G. J. Liu, Y. Qi, F. X. Zhang, C. Li, Angew. Chem. Int. Ed., 2015, 54, 3047-3051.

[62] G. J. Liu, S. Ye, P. L. Yan, F. Q. Xiong, P. Fu, Z. L. Wang, Z. Chen, J. Y. Shi, C. Li, Energy Environ. Sci., 2016, 9, 1327-1334.

[63] T. W. Kim, K. S. Choi, Science, 2014, 343, 990-994.
[64] Y. Huang, Y. Yu, Y. Xin, N. Meng, Y. Yu, B. Zhang, Sci. China Mater., 2017, 60, 193-207.

[65] L. Wang, F. Dionigi, N. T. Nguyen, R. Kirchgeorg, M. Gliech, S. Grigorescu, P. Strasser, P. Schmuki, Chem. Mater., 2015, 27, 2360-2366.

[66] Z. L. Wang, X. Zong, Y. Y. Gao, J. F. Han, Z. Q. Xu, Z. Li, C. M. Ding, S. Y. Wang, C. Li, ACS Appl. Mater. Interf., 2017.

[67] A. Paracchino, N. Mathews, T. Hisatomi, M. Stefik, S. D. Tilley, M. Grätzel, Energy Environ. Sci., 2012, 5, 8673-8681.

[68] J. R. McKone, E. L. Warren, M. J. Bierman, S. W. Boettcher, B. S. Brunschwig, N. S. Lewis, H. B. Gray, Energy Environ. Sci., 2011, 4, 3573-3583.

[69] F. D. Lin, S. W. Boettcher, Nat. Mater., 2014, 13, 81-86.

[70] L. Trotochaud, T. J. Mills, S. W. Boettcher, J. Phys. Chem. Lett., 2013, 4, 931-935.

[71] M. R. Nellist, F. A. L. Laskowski, F. D. Lin, T. J. Mills, S. W. Boettcher, Acc. Chem. Res., 2016, 49, 733-740.

[72] S. Chen, L. W. Wang, Chem. Mater., 2012, 24, 3659-3666.

[73] A. Paracchino, V. Laporte, K. Sivula, M. Grätzel, E. Thimsen, Nat. Mater., 2011, 10, 456.

[74] Z. M. Xia, X. M. Zhou, J. Li, Y. Q. Qu, Sci. Bull., 2015, 60, 1395-1402.

[75] M. J. Kenney, M. Gong, Y. Li, J. Z. Wu, J. Feng, M. Lanza, H. Dai, Science, 2013, 342, 836-840.

[76] C. M. Ding, J. Y. Shi, Z. L. Wang, C. Li, ACS Catal., 2016, 7, 675-688.

[77] P. Peerakiatkhajohn, J. H. Yun, S. Wang, L. Wang, J. Photon. Energy, 2016, 7, 012006.

[78] S. Chu, W. Li, Y. F. Yan, T. Hamann, I. Shih, D. W. Wang, Z. T. Mi, Nano Futures, 2017, 1, 022001.

[79] R. G. Li, Chin. J. Catal., 2017, 38, 5-12.

[80] S. A. Bonke, M. Wiechen, D. R. MacFarlane, L. Spiccia, Energy Environ. Sci., 2015, 8, 2791-2796.

[81] J. S. Luo, J. H. Im, M. T. Mayer, M. Schreier, M. K. Nazeeruddin, N. G. Park, S. D. Tilley, H. J. Fan, M. Grätzel, Science, 2014, 345, 1593-1596.

[82] J. H. Kim, Y. Jo, J. H. Kim, J. W. Jang, H. J. Kang, Y. H. Lee, D. S. Kim, Y. Jun, J. S. Lee, ACS Nano, 2015, 9, 11820-11829.

\title{
高效光解水光电极设计的研究进展
}

\author{
Zhiliang Wang, Lianzhou Wang * \\ 昆士兰大学化学工程学院与生物工程纳米技术澳大利亚研究所, 纳米材料中心, 圣露西亚, 昆士兰4072, 澳大利亚
}

摘要: 光电化学(PEC)分解水过程被认为是由太阳能制氢的一个有前景的路径, PEC的关键在于高效电极的设计. 最近的 十多年里有关材料设计、共催化剂研究和电极制造取得了重大进展, 但仍存在一些关键挑战尚未解决, 包括迫切所需的转 化效率. 作为PEC过程的三个关键步骤: 光采集、电荷转移和表面反应, 发生在很广的时间尺度 $\left(10^{-12}-10^{0} \mathrm{~s}\right)$ 内, 如何组织好 这一连串的步骤以促进各步骤间的无缝协作从而实现高效的PEC过程显得非常重要. 基于高效稳定PEC光电极设计的研 究进展, 本文重点综述了整体考虑的三个主要标准, 总结了一些基本原则和潜在的策略, 尤其讨论了挑战与前景.

关键词: 太阳能; 制氢; 光电极; 光采集; 电荷分离; 表面反应

收稿日期: 2017-09-30. 接受日期: 2017-12-13. 出版日期: 2018-03-05.

*通讯联系人. 电话: +61-7-33654218; 传真: +61-7-33654199; 电子信箱: l.wang@uq.edu.au

基金来源：澳大利亚研究理事会发现(DP)和未来奖学金 $(\mathrm{FF})$ 计划

本文的电子版全文由Elsevier出版社在ScienceDirect上出版(http://www.sciencedirect.com/science/journal/18722067). 